\title{
Reduced cavitation-induced cellular damage by the antioxidative effect of vitamin $E$
}

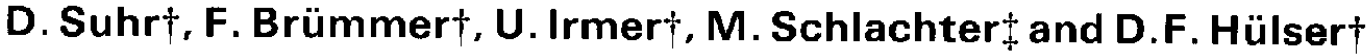 \\ †Biophysics Department, Biology Institute, University of Stuttgart, Pfaffenwaldring 57. \\ D-70550 Stuttgart, Germany \\ ‡F. Hoffmann-La Roche Ltd, CH-4002 Basle, Switzerland
}

Received 15 December 1992

\begin{abstract}
Fragmentation of human urinary and biliary stones by shock waves in extracorporeal lithotripsy is accompanied by tissue damage. Both the fragmentation as well as the side effects are often attributed to cavitation. The hazardous potential of cavitation is not only of a physical nature but also of a chemical nature, because of the generation of free radicals, e.g. $\cdot \mathrm{OH}, \cdot \mathrm{H}$ and $\cdot \mathrm{O}_{2}$. After the application of shock waves, we have demonstrated cavitation-generated free radicals in cell-free solutions and also in the surviving and intact suspended $\mathrm{MGH}-\mathrm{U} 1$ cells by hydroethidine measurements. Under electron microscopical inspection, the same cells exhibited perinuclear cisternae, damaged mitochondria and numerous intracellular vacuoles. The contribution of free radicals to cell damage was investigated by reducing the vitamin $\mathrm{E}$ level in rats by a tocopherol free diet and by incubating $L 1210$ cells in a tocopherol enriched medium. After 250 shock waves, ex vivo erythrocytes revealed a $75 \%$ increase in total cell disruption over cells from non-depleted rats. The in vitro experiments with L1210 cells exhibited a moderate protection by the addition of this scavenger of free radicals.
\end{abstract}

Keywords: lithotripsy; shock waves; free radicals; tocopherol; in vitro; ex vivo

Since 1980 a new technology for the treatment of urinary and biliary calculi has revolutionized the treatment of stone disease. Shock waves - generated extracorporeally by underwater spark discharge, electromagnetic emitters or piezoceramic paraboloids - disintegrate stones inside the human body. The so-called extracorporeal shock wave lithotripsy is a very successful technique, which is applied to most kidney stone patients. The shock-wave treatment, however, is accompanied by side effects like pain, skin petechiae or ecchimosis, haematuria, and organ injury (for reviews see References 1-3).

Cell cultures are damaged or destroyed in a dose dependent manner when cells are treated in suspension ${ }^{4}$. This damage is not related to the origin of cells and is similar for normal and malignant cells ${ }^{5}$, therefore, a physical or chemical cause for these cellular injuries must be assumed which overrules possible biological differences. One major mechanism responsible for these side effects is cavitation, i.e. the generation and movement of bubbles in liquids exposed to tensile stresses. During the collapse of these cavitation bubbles, gas or vapour inside the bubble is nearly adiabatically compressed without heat exchange with the surrounding medium ${ }^{6}$. This results in local 'hot spots', where the high temperature can lead to a homolytic cleavage of molecules, thus generating free

Paper presented at the 'Free Radicals and Ultrasound in Chemistry and Medicine' conference held at the Scientific Societies Lecture Theatre, London, 17-18 December 1992 radicals. These cavitation-induced short lived and highly reactive atoms or molecules have been detected in water by the oxidation of iodide to iodine or $\mathrm{Fe}$ (II) to $\mathrm{Fe}$ (III) after treatment with shock waves ${ }^{7,8}$. Their contribution to cell killing and cell injuries, however, is controversial ${ }^{9,10}$.

Here, we report the intracellular occurrence of shock-wave induced free radicals as was demonstrated with MGH-U1 cells by using hydroethidine, a fluorescent dye suitable for extra- and intracellular measurements and by applying electron microscopical histology. We have also investigated the involvement of free radicals in cell injuries by varying the status of vitamin $E$. Concentrations of tocopherol were reduced in rats by a special diet and increased in L1210 mouse leukemia cells by supplementing the culture medium with this wellknown scavenger of free radicals. The damage of such treated rat erythrocytes and L1210 cells was investigated by flow cytometry after in vitro shock-wave treatment.

\section{Materials and methods}

Experiments with cell cultures: MGH-U1 cells, a human bladder carcinoma line ${ }^{11}$ and probably a subline of T24 (see References 12 and 13), were cultivated as monolayers at $37{ }^{\circ} \mathrm{C}$ and $8 \% \mathrm{CO}_{2}$ in the RPMI 1640 medium (Boehringer Mannheim, Mannheim, Germany), supplemented with $10 \%$ foetal calf serum, $44 \mathrm{mM} \mathrm{NaHCO}$, and antibiotics. Cells were grown to subconfluence, and single cell suspensions $\left(2-3 \times 10^{5}\right.$ cells ml $^{-1}$ in phosphate buffered saline [PBS]) were obtained by a 4 min 
treatment with trypsin (Serva, Heidelberg, Germany; $0.25 \%$ in PBS) and mechanical dispersion.

L1210 cells, a mouse leukemia suspension line ${ }^{14,15}$, were maintained as described for MGH-U1 cells, but the culture medium was additionally supplemented with $180 \mu \mathrm{M}$ sodiumpyruvate and $5 \mu \mathrm{M}$ mercaptoethanol. L1210 cells were cultured for 14 days in the absence or presence of different concentrations of all-rac- $\alpha$ tocopherol $\left(10^{-4}\right.$ to $\left.10^{-2} \mathrm{M}\right)$. Vitamin $\mathrm{E}$ was applied as pure $x$-tocopherol, partially emulsified in the culture medium by a $90 \mathrm{~s}$ sonification (Bransonic 220, Branson, Europe, Soest, The Netherlands), or as an emulsion of $5 \% \alpha$-tocopherol and $15 \%$ modified fish gelatine. Cclls were centrifuged $(5 \mathrm{~min}, 500 \mathrm{~g})$ and washed twice before treatment with fresh culture medium to exclude any effect of extracellular $\alpha$-tocopherol not incorporated into the cell membrane, or of residual gelatine. The final concentration was adjusted to $2-3 \times 10^{5}$ cells $^{-1}{ }^{1}$. The viability of cells after shock-wave treatment was determined by combined measurements with a cell counter (Coulter Counter D Industrial, Coulter Electronics, Hialeah, FL, USA) excluding destroyed cells, and a flow cytometer (FACS-Analyser, Becton-Dickinson, Heidelberg, Germany) using a double staining method for distinguishing viable from dead cells ${ }^{16}$. Cells which hydrolysed fluorescein diacetate and, therefore, exhibited the green fluorescence of fluorescein were considered as viable, whilst cells with membranes which did not exclude the dyc propidium iodide showed a red fluorescence and were counted as dead (for details see Reference 4). Additionally, the growth rates of cells after shock wave treatment and untreated controls were compared for at least 8 days by inoculating equal concentrations of vital cells in suspension-culture flasks and counting aliquots in daily intervals.

Experiments with rat erythrocytes: female rats, strain Ibm: RORO (SPF), were obtained from the Biological Research Laboratories Ltd (Fuellinsdorf, Switzerland). The animals were divided at random into two groups. The controls (Nos 1-6) received a diet adequate in all vitamins and micronutrients. The experimental group (Nos 7-11) was kept on the same diet without vitamin $\mathrm{E}^{17}$. After six weeks the vitamin $\mathrm{E}$ depletion in the experimental group was ascertained by plasma pyruvate kinase (E.C. 2.7.1.40) activity ( $>800 \mathrm{U}^{\text {litre }}{ }^{-1}$ ) (see Reference 17). For further investigation, blood was taken by heart puncture and stabilized with ACD-solution (acidum citricum/dextrose; see Reference 18). Cells were washed with PBS for shock-wave treatment and the final concentration adjusted to $2-4 \times 10^{7}$ cells $\mathrm{ml}^{-1}$. After shock-wave treatment, cells were centrifuged $(10 \mathrm{~min}$, $500 \mathrm{~g}$ ), the number of intact cells was determined in an electronic cell counter, and the amount of free haemoglobin in the supernatant was measured photometrically by the cyano-haemiglobin method (DIN 58 931).

Detection of free radicals: the extra- and intracellular detection of cavitation-generated free radicals has been described ${ }^{19}$. Briefly, we used hydroethidine, a dye which changes fluorescence from blue to red after oxidation to ethidium. The dye has already been used for the intracellular detection of radicals during respiratory burst, in stimulated leukocytes ${ }^{20}$. Hydroethidine is trapped inside the cells after oxidation to ethidium which shows a significant increase in fluorescence after intercalation in the DNA ${ }^{21}$. The fluorescence of shock wave treated cells and controls was determined by flow cytometry, and the fluorescence of dye solutions by spectrofluorometry (LS-3B, Perkin-Elmer, Überlingen, Germany). For each experiment, the change in fluorescence is given as the ratio of the fluorescence of the shock wave treated sample and the untreated control. The significance was tested using the two-sided Mann-Whitney U-test.

Electron microscopical histology: cell cultures were fixed in $2.5 \%$ glutaraldchyde (Merck, Darmstadt, Germany) in $0.1 \mathrm{M} \mathrm{PBS}$ at $\mathrm{pH} 7.1$ for $1 \mathrm{~h}$ at room temperature. Postfixation in 1\% osmium tetroxide (Merck) in $0.1 \mathrm{M}$ PBS was followed by dehydration in ethanol $(8 \mathrm{~min}$ in $40,50,60,70$ and $80 \%$ ethanol, $2 \times 15 \mathrm{~min}$ in $96 \%$ and $100 \%$ ethanol) and propylene oxide $(2 \times 15 \mathrm{~min})$. After impregnation overnight with $2: 1$ and $1: 1$ mixtures of propylene oxide and the epoxy resin Glycidether 100 (former Epon 812, C. Roth, Karlsruhe, Germany) as well as with the pure epoxy resin, respectively, cells were embedded in gelatine capsules and polymerized for $12 \mathrm{~h}$ at $40^{\circ} \mathrm{C}$ and at least $48 \mathrm{~h}$ at $70^{\circ} \mathrm{C}$. Specimens were thin sectioned with a diamond knife on a Reichert OM U3 ultramicrotome (Reichert-Jung, Nußloch, Germany), stained with uranyl acetate and lead citrate and examined with a Zeiss EM 10A electron microscope at $60 \mathrm{kV}$.

Shock-wave treatment: single cell suspensions were transferred into polyethylene pipettes $(4.5 \mathrm{ml}$, Brand, Wertheim, Germany) and treated with shock waves. The pipette ball was submerged in the partially degassed (2.0-2.5 $\mathrm{mg} \mathrm{O}_{2}$ litre $\left.^{-1}, 37^{\circ} \mathrm{C}\right)$ waterbath of an experimental spark-gap lithotripter XL-1 (Dornier Medizintechnik, Germering, Germany) and positioned into the target focus of the brass semi-ellipsoid. Rat erythrocytes and L1210 cells were exposed to shock waves at a repetition frequency of $1 \mathrm{~Hz}$ and a generator voltage of $18 \mathrm{kV}$, MGH-U1 cells and dye solutions at 1 or $8 \mathrm{~Hz}$. Controls were kept in a waterbath at the same temperature and for the same time span as the corresponding shock-wave treated probes. Electrodes were not used for experiments prior to the first 50 and after 1500 electrical discharges.

\section{Results and discussion}

The appearance of cavitation ${ }^{22}$ during extracorporeal shock-wave lithotripsy is not questioned and was often assumed as a mechanism for stone fragmentation ${ }^{23,24}$ and tissue damage ${ }^{25}$. Some publications report evidence for cavitation in vivo: cavitation bubbles were observed by ultrasonic imaging during shock wave exposure of piglets ${ }^{26}$ and dogs ${ }^{27}$ as well as in patients ${ }^{28}$. Acoustic measurements indicated cavitation in rats and mice ${ }^{29}$ and Beagle dogs ${ }^{30}$. Cavitation occurs in liquids and is more frequently observed when cavitation nuclei are present ${ }^{31}$, it appears, therefore, also in vivo in the interstitial space or in liquid-filled cavities. Along with the mechanical effects of cavitation - surface ablation by jet streams of high velocity accelerated from asymmetrically collapsing bubbles - there also exist chemical effects mediated by cavitation-generated free radicals. With different probes sensitive to oxidation, free radicals have been demonstrated after shock-wave application to cell free solutions $7,8,19$

The incidence of intracellular cavitation is uncertain, but cavitation-generated free radicals could explain the intracellular damage in otherwise intact cells after shock-wave treatment of cell suspensions ${ }^{32.33}$. We, therefore, used hydroethidine, a fluorescent dye suitable for the detection of extra- and intracellular free radicals and were successful in demonstrating an increase of 


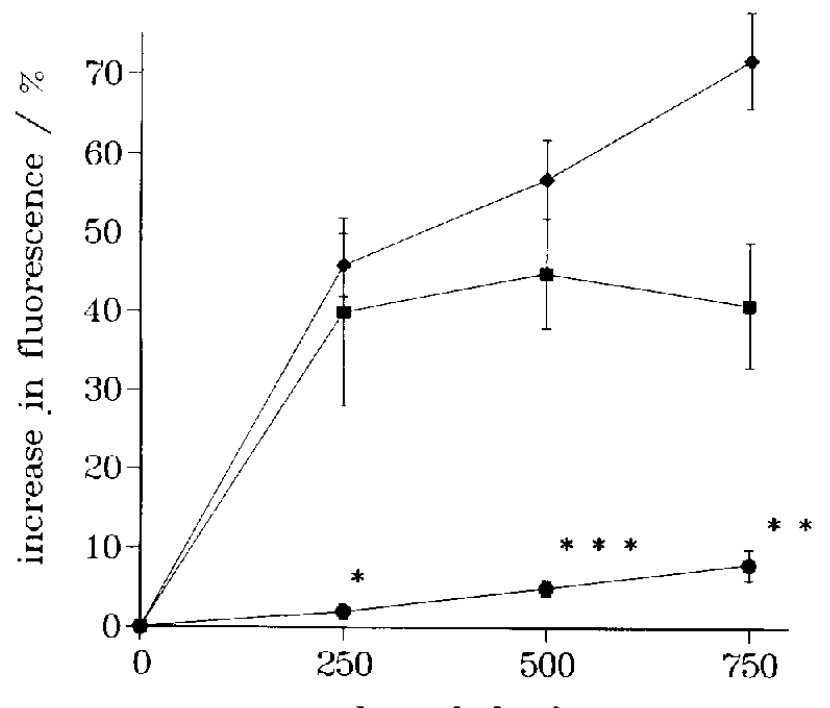

number of shock waves

Figure 1 Cavitation-generated free radicals, demonstrated by an increase in the fluorescence of the oxidation product ethidium after shock-wave treatment. The increase in free radicals in dye-incubated MGH-U1 cells, repetition frequency $8 \mathrm{~Hz}$ (e, values for shock wave treated cells differ with ${ }^{*} \alpha<0.05,{ }^{*} \alpha<0.02$, and ${ }^{* * *} \alpha<0.01$ versus control) is not as high as in cell-free dye solutions treated under the same conditions $(\bullet)$. At a repetition frequency of $8 \mathrm{~Hz}(\bullet)$ more free radicals are detected than at $1 \mathrm{~Hz}(\boldsymbol{D})$. In cell-free solutions, all values for shock-wave treated samples differ with $\alpha<0.01$ from the control

intracellular free radicals after shock-wave treatment at a repetition frequency of $8 \mathrm{~Hz}$ (Figure 1). The increase of intracellular fluorescence in geometrically intact cells is less pronounced than in cell-free dye solutions, which may be explained by dye loss through transient membrane ruptures ${ }^{19,33-35}$. The amount of extracellularly produced free radicals at a repetition frequency of $8 \mathrm{~Hz}$ is higher than at $1 \mathrm{~Hz}$. This is attributable to a higher cavitational activity, because collapsed cavitation bubbles act as cavitation nuclei with a very short lifetime. With increasing shock-wave repetition-frequency, therefore, an increasing number of cavitation nuclei is observed?

The origin of the shock-wave induced intracellular free radicals is not quite understood. These radicals may be generated in intracellular microcavitation, but most of the cells, which were subject to an intracellular cavitation, will presumably be destroyed. These cells are not distinguishable from cells destroyed by extracellular cavitation, e.g. via microjets or shear stresses. Destroyed cells, however, cannot be detected with flow cytometry, the measured intracellular increase in radical-induced fluorescence, therefore, is only due to cells which remain geometrically intact. Intracellular cavitation depends on intracellular cavitation nuclei which could be present in liquid-filled vacuoles found in MGH-U1 cells ${ }^{12}$ (Figure 2a). Obviously, conditions for the initiation of intracellular cavitation are given but since the threshold for cavitation is rather high in liquids of high viscosity ${ }^{24,36}$, the high intracellular viscosity may keep expanding cavitation bubbles within a cell small, and prevent the total cell disrupture. Otherwise, intact cells are then characterized by alterations in shape and ultrastructure of mitochondria as well as of the nuclear envelope (Figure $2 b$ ). Occasionally, cells can be severely damaged and look like spherical ghosts with destroyed intracellular organelles, but they are still surrounded by an intact cell membrane (Figure
$2 c$ ). Both types of cellular damage may be identified but not distinguished by an increased intracellular fluorescence after oxidation of hydroethidine. Whether free radicals are intracellularly produced by sonochemically active cavitation bubbles or are released from endogenous pools
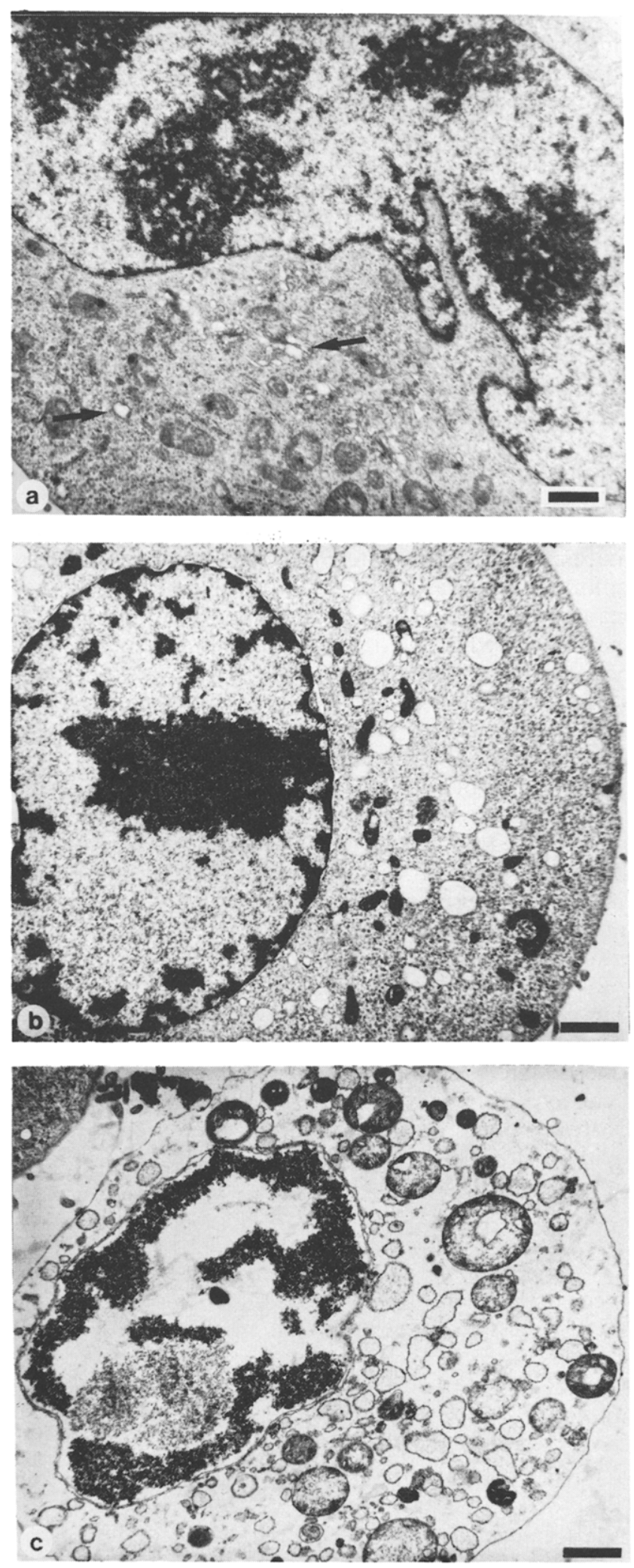

Figure 2 Electron micrograph of MGH-U1 cells: (a) control, arrows point to vacuoles, the potential cavitation nuclei. After treatment with shock waves (b) large perinuclear cisternae, altered shape and uitrastructure of mitochondria, and enlarged vacuoles are observed as well as (c) spherical ghosts without intact intracellular structures but intact cell membranes. Bar: $1 \mu \mathrm{m}$ 
of free radicals remains unclear. Mechanically injured mitochondria could be such a source for free radicals escaping the respiration chain. Another explanation for the occurrence of intracellular free radicals would be extracellular cavitation and diffusion of radicals across the cell membrane into the cytoplasm. In this case, however, radicals would rather react with the polyunsaturated fatty acids of the cell membrane ${ }^{37}$.

Free radicals cause severe tissue damage leading to a release of cytoplasmic proteins, e.g. the Tamm-Horsfall protein $^{38}$, which was also measured in the urine of patients as a parameter for kidney damage after shock-wave lithotripsy ${ }^{39}$. We, therefore, investigated in vitro the contribution of cavitation-generated free radicals to shock wave-induced cell damage by varying the cellular amount of vitamin $\mathrm{E}$, a scavenger of free radicals. Vitamin $\mathrm{E}$ is a generic term that includes all compounds exhibiting the biological activity of $\alpha$-tocopherol. This major lipid soluble antioxidant captures free radicals, terminates the lipid peroxidation chain reaction and thus protects the polyunsaturated fatty acids in cellular and subcellular membranes ${ }^{37}$. An increase in the concentration of this endogenous scavenger of free radicals should protect the cells with less disturbance of the cellular physiology than other compounds, which also influence the cellular antioxidative defence status ${ }^{19}$. We performed two different approaches to varying the cellular tocopherol level: (1) ex vivo study: reduction of the vitamin $\mathrm{E}$ concentration in rats by a tocopherol-free diet and subsequent treatment of these rat erythrocytes with shock waves; (2) in vitro study: direct supplementation of cell culture medium with $\alpha$-tocopherol and shock wave treatment of these L1210 cells.

The haemolysis of erythrocytes of tocopherolsupplemented and -depleted rats was determined after shock-wave treatment. The photometrical determination of free haemoglobin demonstrated a difference $(\alpha<0.01)$ in sensitivity between the two groups (Figure 3), indicating a protecting effect of tocopherol against shock wave induced cell damage: $28.8 \pm 2.7 \%$ (mean \pm s.d.) of the total haemoglobin was released after 250 shock waves from erythrocytes of the control group, against $37.1 \pm 9.9 \%$ from those of the tocopherol-depleted animals. The difference between the two groups was more pronounced, however, when the percentage of geometrically destroyed erythrocytes after 250 shock waves was determined with

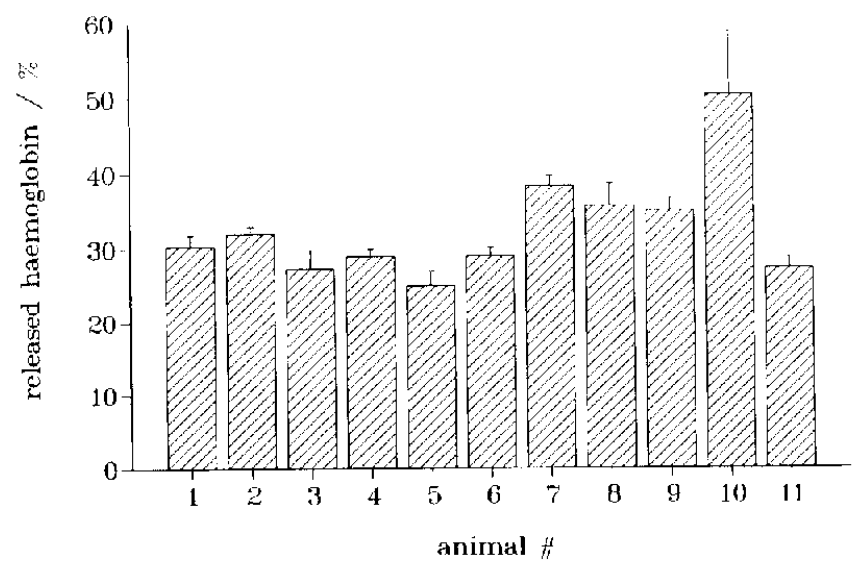

Figure 3 Percentage of released haemoglobin in the supernatan after treatment with 250 shock waves. A slight but significant $(\alpha<0.01)$ difference between control (Nos 1-6) and tocopheroldepleted experimental group (Nos 7-11) is distinguishable

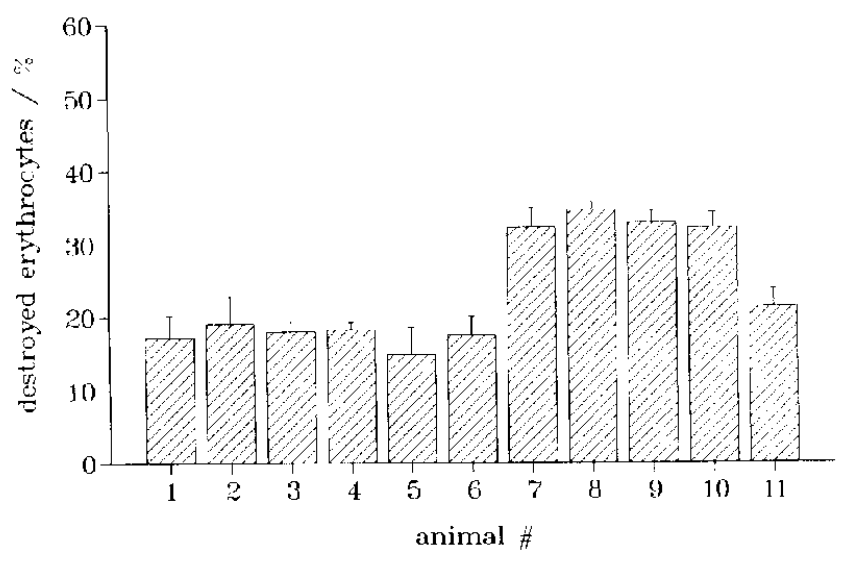

Figure 4 Percentage of destroyed rat erythrocytes after treatment with 250 shock waves. Note the difference $(\alpha<0.01)$ between the control (Nos 1-6) and the tocopherol-depleted experimental group (Nos 711 ), where roughly twice as many erythrocytes were destroyed

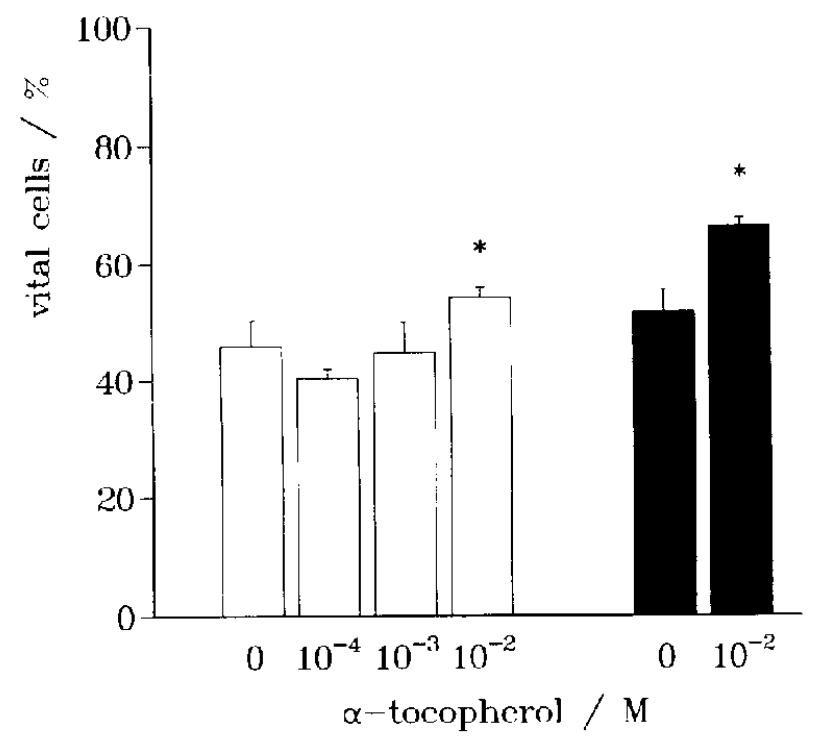

Figure 5 Protective effect of $10^{-2} \mathrm{M} x$-tocopherol on the viability of L1210 cells which were treated with 250 shock waves at a repetition frequency of $1(\square)$ and $8(\square) \mathrm{Hz}$. " $x<0.1$

a cell counter: $17.5 \pm 1.4 \%$ for the control animals against $30.6 \pm 5.3 \%$ for the tocopherol-depleted rats (Figure 4 ). The difference between the percentage of destroyed erythrocytes and the amount of released haemoglobin is due to haemoglobin release through transient membrane ruptures in geometrically intact erythrocytes. Since the membrane permeability of erythrocytes from tocopheroldepleted rals is increased, the amount of haemoglobin per erythrocyte is diminished. In spite of the higher amount of destroyed cells, the release of free haemoglobin after shock-wave treatment is, therefore, only slightly increased in tocopherol-depleted erythrocytes.

The tocopherol depletion of rats was ascertained by an increased serum pyruvate kinase activity. This pyruvate kinase, however, is released from necrotic rat tissue during depletion due to a decreased mechanical stability. This decreased stability may also be detectable for erythrocytes and could aggravale the differentiation between mechanical and chemical effects of shock waves and cavitation. The increased haemolysis of shock wave treated erythrocytes from tocopherol-depleted rats, 
therefore, may not be solely attributable to an increased effect of free radicals.

A more sensitive method than the determination of acute cell death and of free radicals after shock-wave treatment may be the investigation of long-term effects, since cells injured by shock waves and free radicals are altered physiologically. As could be demonstrated with $\alpha$-tocopherol pretreated L1210 cells exposed to 250 shock waves, a protective effect is visible after a lag-phase of $72 \mathrm{~h}$ (Figure 6), when the pretreated cells started somewhat faster into the exponential replication phase. For these experiments, the exact concentration of bioavailable $\alpha$-tocopherol cannot be given, since the emulsification by ultrasound may already have oxidized some amount of tocopherol by cavitation. Furthermore, reaggregated fat droplets were visible on the medium surface. To circumvent this handling problem of the lipophilic substance, a concentration dependence was tested by the application of an emulsion of $\alpha$-tocopherol and fish gelatine. In contrast to pure $\alpha$-tocopherol, this emulsion allowed the application of different defined concentrations, because tocopherol droplets in the nanometre range are stabilized by the gelatine and may be available to the cells by phagocytosis. The given
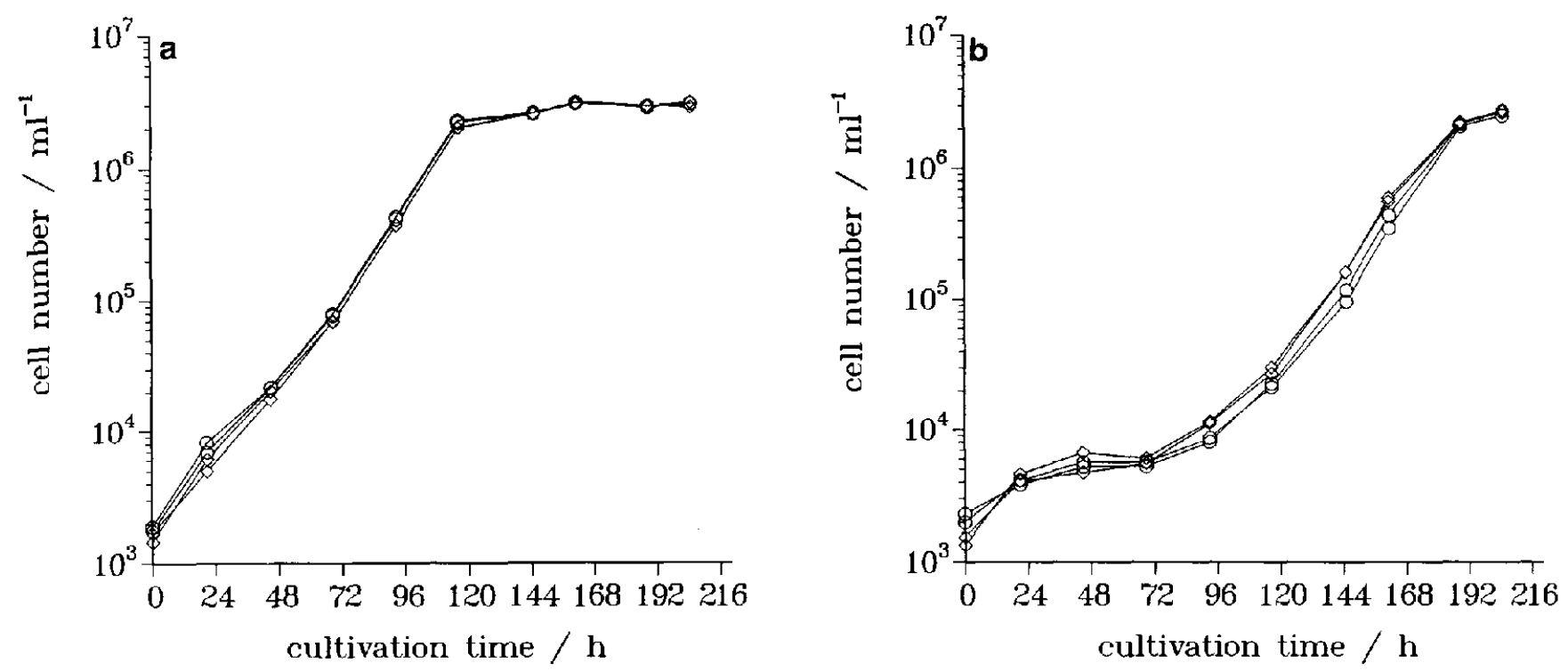

Figure 6 (a) L1210 cells were grown for 14 days in the absence (O) or presence $(\diamond)$ of $10^{-3} \mathrm{M}$ pure $\alpha$-tocopherol, partially emulsified by sonification. At time point 0 the cells were inoculated and cultured in medium without tocopherol. Control and tocopherol treated cells were each counted in two independent experiments. (b) L1210 cells grown as in (a) but inoculated and cultured after a treatment with 250 shock waves. All cells revealed a lag phase of 72 hours. L1210 cells supplemented with $\alpha$-tocopherol ( $\diamond)$ were somewhat accelerated in growth as compared with the control cells (O)
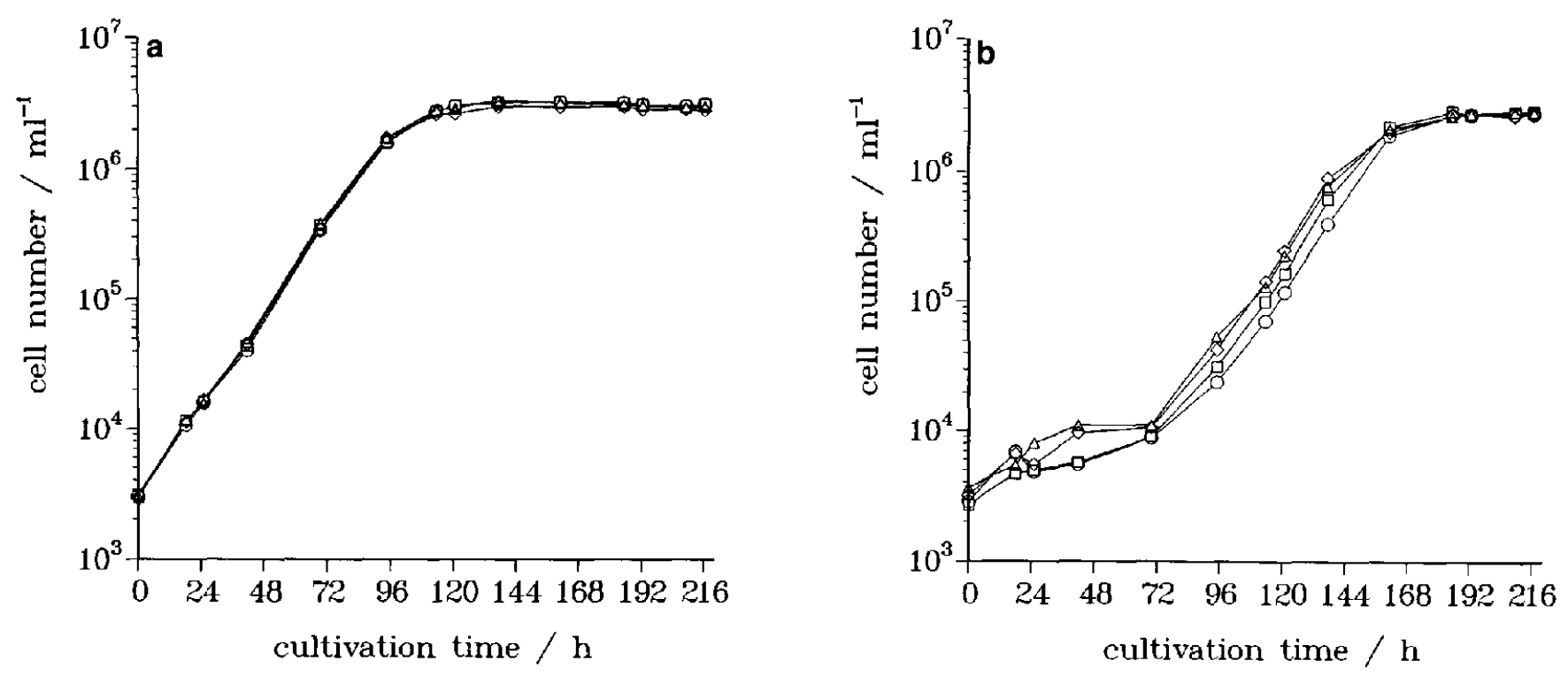

Figure 7 (a) L1210 cells were grown for 14 days in the absence or presence of different concentrations of $\alpha$-tocopherol, applied as an emulsion of $5 \% \alpha$-tocopherol and $15 \%$ fish gelatine. At time point 0 , cells were inoculated and cultured in medium without tocopherol. (O) control without $\alpha$-tocopherol, (D) cultured with $10^{-4} \mathrm{M}$, (O) $10^{-3} \mathrm{M}$, and ( $\triangle$ ) $10^{-2} \mathrm{M} \alpha$-tocopherol for 14 days before inoculation. (b) L1210 cells grown as in (a) but inoculated and cultured after a treatment with 250 shock waves. Again, all cells had a lag phase of 72 hours, and cells supplemented with $\alpha$-tocopherol revealed a concentration dependent acceleration in growth as compared with the contral cells. (O) control without $\alpha$-tocopherol, ( $\square$ ) cultured with $10^{-4} \mathrm{M}$, ( $\left.\diamond\right) 10^{3} \mathrm{M}$, and $(\triangle)$ $10^{-2} \mathrm{M} \alpha$-tocopherol for 14 days before shock wave treatment and inoculation 
concentrations of the water-insoluble $\alpha$-tocopherol, however, will be an estimation of the highest possible concentration, and do not represent the effective concentration for the cells.

The acute viability of $\mathrm{L} 1210$ cells exposed to 250 shock waves, after being cultured in the presence of $\alpha$-tocopherol also demonstrated the protective effect of the highest concentration (Figure 5). The protection of $10^{-2} \mathrm{M}$ $\alpha$-tocopherol was more pronounced for a shock wave repetition frequency of $8 \mathrm{~Hz}(\alpha<0.1)$, when more free radicals are produced than at $1 \mathrm{~Hz}(\alpha<0.1)$, as has already been shown in Figure 1 (significance level cannot exceed 0.1 because only three experiments were performed).

The protective effect of $x$-tocopherol could also be demonstrated in a concentration dependent manner for the long-term investigation of the growth rate (Figure 7). Again, after a lag phase of $72 \mathrm{~h}$, the cells supplemented with vitamin $\mathrm{E}$ before the shock-wave treatment proliferated faster than control cells. This lag phase of $72 \mathrm{~h}$ after shock-wave treatment was not observed in former experiments, where L1210 cells were inoculated after the shock-wave treatment and showed a similar growth rate as the control cells ${ }^{4}$. The sensitivity of L1210 cells on shock waves did not change from that of the previous experiments, as was proved with cells of an earlier passage number. Therefore, this difference must be attributed to changes in the experimental set-up, e.g. lower gas content of the lithotripter waterbath.

The protective effect of tocopherol against shock-wave induced cell damage, as we have demonstrated with ex vivo and in vitro experiments, may not be valid in vivo. Strohmaier and colleagues ${ }^{40,41}$, however, have described a protective effect of fosfomycin in vitro and verapamil in vitro and in vivo both in animals and patients. This correlation of in vitro and in vivo experiments encouraged us to initiate an in vivo study of the protective effects of antioxidative vitamins in lithotripsy patients.

\section{Conclusions}

We have demonstrated the extra- and intracellular occurrence of cavitation-induced free radicals after shock-wave treatment and have investigated the influence of the radical scavenger $\alpha$-tocopherol on the viability of such like-treated cells. Since tocopherol increased the viability in ex vivo as well as in in vitro experiments, we conclude that free radicals contribute to some extent to the shock-wave induced cellular damage.

\section{Acknowledgements}

This work was supported by the Bundesministerium für Forschung und Technologie and by F. Hoffmann-La Roche Ltd, Basle, Switzerland. We would like to thank Mrs B. Rehkopf and Mrs K. Laskowski for excellent technical assistance.

\section{References}

1 Lingeman, J.E., McAteer, J.A., Kempson, S.A. and Evan, A.P. Bioeffects of extracorporeal shock-wave lithotripsy. Strategy for research and treatment Urol Clin North Am (1988) 15 507-514

2 Brümmer, F., Bräuner, Th. and Hülser, D.F. Biological effects of shock waves World J Urol (1990) 8 224-232

3 Eisenberger, F., Miller, K. and Rassweiler, J. (Eds) Stone Therapy in Urology Georg. Thieme Verlag, Stuttgart, Germany (1991)
4 Brümmer, F., Brenner, J., Bräuner, Th. and Hülser, D.F. Effect of shock waves on suspended and immobilized L1210 cells U/trasound Med Biol (1989) 15 229-239

5 Brümmer, F., Suhr, D. and Hülser, D.F. Sensitivity of normal and malignant cells to shock waves $J$ Stone Dis (1992) 4243248

6 Flint, E.B. and Suslick, K.S. The temperature of edvitation Science (1991) 253 1397-1399

7 Henglein, A., Gutiérrez, M. and Ulrich, R. Oxidation of iodide by the intense acoustic bursts of an extracorporeal lithotripter Int $J$ Radiat Biol (1988) 54 123-126

8 Morgan, T.R., Laudone, V.P., Heston, W.D.W., Zeitz, L. and Fair, W.R. Free radical production by high energy shock waves comparison with ionizing irradiation J Urol (1988) 139 186-189

9 Suhr, D., Brümmer, F. and Hülser, D.F. Are biological effects of shock waves caused by frce radicals? In Ultrasonics International 91 Conference Proceedings Butterworth-Heinemann, Oxford, UK (1991) $57-60$

10 Gambihler, S. and Delius, M. Influence of dissolved and free gases on iodine release and cell killing by shock waves in vitro. Ultrasound Med Biol (1992) 18 617-623

11 Evans, D.R., Irwin, R.J., Havre, P.A., Bouchard, J.G., Kato, T. and Prout, G.R. The activity of the pyrimidine biosynthetic pathway in MGH-U1 transitional carcinoma cells grown in tissue culture I Urol (1977) 117 712-719

12 Bubenik, J., Baresova, M., Viklicky, V., Jakoubkova, J., Sainerova, H. and Donner, J. Fstablished cell line of urinary bladder carcinoma (T24) containing tumour-specific antigen Int $J$ Cancer (1973) $11765-773$

13 O'Toole, C.M., Povey, S., Hepburn, P. and Franks, L.M. Identity of some human bladder cancer cell lines Nuture (1983) 301 429-430

14 Law, I.W., Dunn, T.B., Boyle, P.J. and Miller, J.H. Observations on the effect of a folic-acid antagonist on transplantable lymphoid leukemias in mice $J$ Natl Cancer Inst (1949) 10 179-192

15 Iutchison, D.J., Ittensohn, O.L. and Bjerregaard, M.R. Growth of L1210 mouse leukemia cells in vitro. Exp Cell Res (1966) 42 $157-170$

16 Jones, K.H. and Senft, J.A. An improved method to determine cell viability by simultaneous staining with fluorescein diacetate propidium iodide $J$ Histochem Cytochem (1985) 33 77-79

17 Weiser, H., Vecchi, M. and Schlachter, M. Stereoisomers of $\alpha$-tocopheryl acetate. III. Simultaneous determination of resorptiongestation and myopathy in rats as a mcans of evaluating biopotency ratios of all-rac- and RRR- $x$-tocopheryl acetate Int $J$ $V$ it Nutr Res (1985) 55 149-158

18 Richterich, R. ACD-Lösung In Klinische Chemie - Theorie und Praxis 3rd Edn, S. Karger, Basle, Switzerland (1971)

19 Suhr, D., Brümmer, F. and Hülser, D.F. Cavitation-generated free radicals during shock wave exposure: investigations with cell-free solutions and suspended cells Ultrusound Med Biol (1991) 17 $761-768$

20 Rothe, $\mathbf{G}$, and Valet, G. Flow cytometric analysis of respiratury burst activity in phagocytes with hydroethidine and $2^{\prime}, 7^{\prime}$ dichlorofluorescin $J$ Leukocyte Biol (1990) 47440448

21 LePecq, J.B. and Paoletti, C. A fluorescent complex between ethidium bromide and nucleic acids. Physical-chemical characterization J Mol Biol (1967) 27 87-106

22 Coleman, A.J., Saunders, J.E., Crum, L.A. and Dyson, M. Acoustic cavitation generated by an extracorporeal shockwave lithotripter Ultrasound Med Biol (1987) 13 69-76

23 Crum, L.A. Cavitation microjets as a contributory mechanism for renal calculi disintegration in ESWL $J$ U rol (1988) $1401587 \cdot 1590$

24 Delius, M., Heine, G. and Brendel, W. A mechanism of gallstone destruction by extracorporeal shock waves Naturwissenschaften (1988) 75 200-201

25 Fischer, N., Muller, H.M., Gulhan, A., Sohn, M., Deutz, F.J., Rubben, H. and Lutzeyer, W. Cavitation effects: possible cause of tissue injury during extracorporcal shock wave lithotripsy $J$ Endourol (1988) 2 215-220

26 Delius, M., Denk, R., Berding, C., Liebich, H.-G., Jordan, M. and Brendel, W. Biological effects of shock waves: Cavitation by shock waves in piglet liver Ultrasound Med Biol (1990) 16 467-472

27 Kuwahara, M.A., Ioritani, N., Kambe, K., Shirai, S., Taguchi, K., Saitoh, T., Orikasa, S., Takayama, K., Aida, S. and Iwama, N. Hyperechoic region induced by focused shock waves in vitro and in tivo: Possibility of acoustic cavitation bubbles $J$ Lithotripsy \& Stone Dis (1990) 1282.288

28 Zeman, R.K., Davros, W.J., Goldberg, J.A., Garra, B.S., Hayes, W.S., Cattau, E.L., Horii, S.C., Cooper, C.J. and Silvermans, P.M. Cavitation effects during lithotripsy. Part II. Clinical observations Radiology (1990) 177 163-166

29 Riedlinger, R., Ueberle, F. and Zanger, U. HEPUS (High energy 
pulsed ultrasound): Apparatus and physical aspects of tumorinsonification Biomed Technik (1988) 33(Suppl. 2) 139-140

30 Williams, A.R., Delius, M., Miller, D.L. and Schwarze, W. Investigation of cavitation in flowing media by lithotripter shock waves both in vitro and in vivo. Ultrasound Med Biol (1989) 15 53-60

31 Dear, J.P., Field, J.E. and Walton, A.J. Gas compression and jet formation in cavities collapsed by a shock wave Nature (1988) $332505-508$

32 Russo, P., Mies, C., Huryk, R., Heston, W.D.W. and Fair, W.R. Histopathologic and ultrastructural correlates of tumor growth suppression by high energy shock waves $J$ Urol (1987) 137 338-341

33 Bräuner, Th., Brümmer, F. and Hülser, D.F. Histopathology of shock wave treated tumor cell suspensions and multicell spheroids Ultrasound Med Biol (1989) 15 451-460

34 Schiess, K. Permeabilitätsänderung der Plasmamembran von MGH-U1-Zellen nach Stoßwellenbehandlung (1989) Diploma thesis, Biology Institute, University of Stuttgar

35 Gambihler, $S$, and Delius, M. Transient increase in membrane permeability of L1210 cells upon exposure to lithotripter shock waves in vitro. Naturwissenschaften (1992) 79 328-329

36 Bräuner, Th., Brïmmer, F., Hülser, D.F. and Rassweiler, J. Biological side effects of shock waves. In Stone Therapy in Urology (Eds Eisenberger, F., Miller, K. and Rassweiler, J.) Georg Thieme Verlag, Stuttgart, Germany (1991) Chapter 3.9 50-63

37 Halliwell, B. and Gutteridge, J.M.C. Free Radicals in Biology and Medicine Clarendon Press, Oxford, UK (1985)

38 Bakris, G.L., Gaber, A.O. and Jones, A.D. Oxygen free radical involvement in urinary Tamm-Horsfall protein excretion after intrarenal injection of contrast medium Radiology (1990) 175 $57-60$

39 Wilbert, D.M., Strohmaier, W.L., Flüchter, S.H. and Bichler, K.H. Urinary proteins as parameters of renal functional changes after extracorporeal shock wave lithotripsy Invest Urol (1989) 3249-253

40 Strohmaier, W.L., Pedro, M., Wilbert, D.M. and Bichler, K.H Reduction of shock wave induced tubular alteration by fosfomycin $J$ Endourol (1991) $557-60$

41 Strohmaier, W.L Bichler, K.H., Koch, J., Balk, N. and Wilbert, D.M. Protective effect of verapamil on shock wave induced renotubular dysfunction $J$ Urol (in press) 